\title{
The Alternative
}

\author{
Lisa Nandy MP, Caroline Lucas MP and Chris Bowers (Eds.) 2016 \\ Biteback Publishing, London, UK \\ ISBN 978-1-78590-049-5, pp. 368, ebook, NZD30.00
}

$\mathrm{F}$ or decades, social workers have witnessed the fallout of the neoliberal experiment, including runaway inequality, poverty, and compromised health and education systems. While the difficulty of operating in this environment has intensified focus within social work on critical and radical practice, greater gains demand Statelevel rethinks of social and economic policy. Yet, political momentum for such radical reconfiguration is often lacking. One might be forgiven for wondering: "whatever happened to progressive politics?"

In this context, The Alternative, an edited collection from the United Kingdom (UK), comes not a moment too soon. Compiled during the soul-searching following the Conservative Party's resounding 2015 electoral success, The Alternative seeks to initiate conversation about reviving progressive politics in the UK, and the mechanics of building a new, progressive vision for the country. The core provocation of the book's editors-Labour MP, Lisa Nandy; Green MP, Caroline Lucas; and former Liberal Democrat Councillor and Parliamentary candidate, Chris Bowers-is that UK progressives (whether in Westminster or not) should shelve "tribalism" and in-fighting (p. xxi) in order to work together, because cooperation offers the best hope of ousting the Conservatives (in the short term) and implementing a progressive programme (in the long term). They also urge progressives to start proactively defining themselves by what they believe in and stand for, not just by who or what they disagree with, and to reconnect with disenchanted grassroots political activists.

Structurally, the book has two sections. Section One explores progressives' shared values, ideas and politics; Section Two considers how to effect cooperation across the progressive spectrum. The decision to dedicate an entire section to unpicking progressive values was wise, given the term progressive is often bandied about or conflated with the Left, but also because the exploration has rendered the book a valuable resource for those seeking a considered articulation of contemporary progressive ideals. Section Two's candid evaluation of both the opportunities and difficulties of collaboration adds a healthy dose of realism to the book's enterprise, allowing it to overcome any accusation of wishful idealism.

Contributions come from an impressive array of individuals, making The Alternative a treasure trove of thought-provoking, creative ideas, although arguably at the cost of a more unified message (evidently not all contributors sing from the same progressive song sheet). Understandably, given the book's editors, chapters from politicians (both former and current) abound-from parliamentary candidates, MPs, and Members of the House of Lords, to the leader of the Danish progressive party, The Alternative (Uffe Elbæk). The book also includes third-sector campaigners (Katie Ghose of the Electoral Reform Society, Siân Berry and Stephen Joseph of the Campaign for Better Transport, and Carys Afoko of SumOfUs), unionists (Frances O'Grady), commentators (Yasmin Alibhai-Brown and Zoe Williams), and academics and representatives of institutes (Andrew Simms, Jonathan Rowson, John Curtice, Indra Adnan), among others. With some exceptions, chapters adopt a boots-on-the-ground/informed-commentator perspective, drawing insights from the contributors' cumulative years of practical 
experience rather than extensive referencing. This approach may disappoint readers seeking greater theoretical grounding, although they may enjoy Rowson's in-depth, semi-spiritual deconstruction of the notion progressive.

The Alternative targets political, policy and activist circles, so relevance to social workers is indirect. Yet, its broad thematic sweep-covering topics as wide-ranging as social security, planning, migration, political cooperation, housing, public services, climate change, foreign policy, communications and political correctness-particularly in Section One, offers something for everyone. Furthermore, its outside-the-box thinking is both inspirational and semi-instructional for anyone interested in lateral and radical thinking. Evidently, contributions are UK-focused, rendering certain aspects less useful for a New Zealand audience-most obviously, the recurring case for a proportional representation system for UK national elections. However, other chapters could have been written for New Zealand, such as Berry and Joseph's excellent contribution on planning policy that advocates, inter alia, greater proximity between people and services, more effective public transport systems, and housing developments that foster real communities rather than upholding "a syndrome now deep in the national psyche about housing as an investment" (p. 78).

Other applicable chapters include those by David Boyle, Jonathan Edwards or Zoe Williams, which advocate horizontal politics, devolved power, and/or recognition of local, community-based activities. These chapters demonstrate the latent assets and strengths in communities that are often under-supported-communities in which social workers often work. Meanwhile, Ruth Lister's chapter on social security analyses alternative mechanisms for achieving poverty prevention and social distribution, including more inclusive contributory social insurance systems or a universal basic income. Guided by her anti-poverty research, Lister also sounds a warning to anyone working with people on low incomes about stigmatising language and social discourse, and calls for "a culture of human rights" to replace the current "culture of institutionalised suspicion" (p. 35).

Finally, Norman Lamb and Steve Reed's searing assessment of UK public services would propel any public servant to critically reflect on their own practice and institutional context. Indeed, Lamb and Reed's analysis of the defects in bureaucratic, top-down approaches resonates with oft-made observations in social work literature. Their practical proposals for ensuring we "unleash the vitality of people working in public services and the insight of those who use them" (p. 46) offer food for thought, including mutualised services (for both service users and staff), and individualised budgets permitting service users to decide how to spend money allocated to them.

The Alternative went to publication a week after the Brexit referendum result, a massive blow to progressives in the UK and worldwide. The editors note that this timing underscores the "urgency and timeliness" of the book's message (p. vii). However, it also meant contributors sidestepped the disillusioned anger plaguing progressives in the aftermath of both Brexit and Trump's election as President of the United States of America. While the activities of protest and reaction following these events are understandable and necessary, they must not detract from the positive, proactive task of reimagining politics, society and economics. In this climate, The Alternative's greatest offering-its self-professed and well-realised tone of optimism-bolsters its openness to imagine and identify creative, credible, progressive ideas. This sentiment should hearten and motivate anyone passionate about critical, radical change, and the forging of more ambitiously progressive society. 